\title{
Risk factors for social isolation among older adults in long-term care: A scoping review
}

Sheila A. Boamah, RN, PhD ${ }^{1 *}$, Rachel Weldrick, MA ${ }^{2}$, Tin-Suet Joan Lee ${ }^{1}$, and Nicole Taylor, $\mathrm{BSc}^{1}$

${ }^{1}$ McMaster University, Faculty of Health Sciences, Hamilton, Ontario, Canada

${ }^{2}$ McMaster University, Faculty of Social Science, Hamilton, Ontario, Canada

\begin{abstract}
Objectives: A wealth of literature has established risk factors for social isolation among older people, however much of this research has focused on community-dwelling populations.

Relatively little is known about how risk of social isolation is experienced among those living in long-term care (LTC) homes. We conducted a scoping review to identify possible risk factors for social isolation among older adults living in LTC homes. Methods: A systematic search of five online databases retrieved 1535 unique articles. Eight studies met the inclusion criteria. Results: Thematic analyses revealed that possible risk factors exist at three levels: individual (e.g., communication barriers), systems (e.g., location of LTC facility), and structural factors (e.g., discrimination). Discussion: Our review identified several risk factors for social isolation that have been previously documented in literature, in addition to several risks that may be unique to those living in LTC homes. Results highlight several scholarly and practical implications.
\end{abstract}

Keywords: Social isolation, risk factors, older adults, long-term care

\section{Corresponding author}

Sheila A. Boamah

School of Nursing, Faculty of Health Sciences

McMaster University, 1280 Main St. W.

Hamilton, ON, Canada L8S 4K1

boamahs@mcmaster.ca 


\section{Introduction}

Social isolation is a growing public health concern that affects many older people (Santini et al., 2020) and was declared a global epidemic amongst the older adult population by the U.S Surgeon General (Murthy, 2017). Globally, up to 50\% of older persons over 60 years of age are at risk of social isolation (Ibrahim et al., 2013; Landeiro et al., 2017). Older people are heterogenous group in terms of their ability to engage and remain fully active. While some continue to thrive in older age, others disengage. A section of the older population experience good health, but others experience a significant loss of capacity which places them at increased risk of social isolation and loneliness (Courtin \& Knapp, 2017; Holt-Lunstad et al., 2010). Increased social isolation among older adults can be a result of a variety of factors, including family dispersal, loss of loved ones and peers, retirement, decreased mobility and income, and declining health (Cornwell \& Waite, 2009; Courtin \& Knapp, 2017; Heffner et al., 2011; Steptoe et al., 2013). In a meta-analytic review, Holt-Lunstad et al. (2015) correlated social isolation with lifestyle behaviours such as smoking and high alcohol consumption, all of which are well-established risk factors for premature mortality. A recent study found that high levels of perceived social isolation in older adults was associated with increased levels of depressive and anxiety symptoms (Santini et al., 2020). Further, a cross-sectional analysis of data from the National Health and Aging Trends study found a segment of the older population to be at a higher risk of social isolation and reported differences in sociodemographic factors, including race, income, being 80 or older, a woman, an immigrant, or a member of minority group, and those living with health issues, such as chronic illnesses and disabilities (CloutierFisher et al., 2011; Cudjoe et al., 2020; The National Seniors Council, 2014). Additionally, it has been observed that place of residence, in particular, nursing homes can exacerbate social 
isolation and loneliness potentially due to increased dependency and a lack of intimate relationships (British Columbia Ministry of Health, 2004).

Social integration plays an important role in maintaining the health and psychological well-being of older adults (Lehning et al., 2015). Social integration implies a sense of belonging and refers to the extent to which an individual participates in a broad range of social exchanges with others (Ajrouch et al., 2001), whether it is the family, social networks, or in their communities. Promoting social integration amongst older people is important for improving their physical and mental health as socialization and activities are indicators of productive and healthy aging and have been shown to improve cognitive function, independence (Holt-Lunstad et al., 2010; Uchino, 2006) and overall longevity (Holt-Lunstad et al., 2010; Shor et al., 2013). Social integration is a multidimensional phenomenon. In the aging literature, there are nuances in the discourse on social integration in relation to societal and institutional factors that constrain access to integration. For instance, poor health and low income can act as barriers to participating in social activities and thereby increase isolation and exclusion among older adults. Over the life course, the structure and quality of social relations may be altered by changes in functional capacity. It is well-known that heterogeneity exists in both the structural and support characteristics of those relationships (Consedine et al., 2004). Typically, the social support networks for older adults tend to be smaller and centered on close friends and family compared to those of younger groups (Ajrouch et al., 2001). Increasing the social integration of older adults is of vital importance as it can alleviate the devastating sense of isolation and loneliness and improve the quality of life of older adults living alone in the community and those who utilize long-term care services (Cattan et al., 2005). 
As the global population continues to rise, the number of older persons, those aged 65 years or older is projected to double to 1.5 billion by 2050 , representing $16 \%$ of the world population (United Nations, 2019). The 'demographic imperative' of a progressively aging society places unprecedented demands on health care systems across the globe, their workforce and budgets. The current health services especially in high-income countries are not adequately aligned to meet the needs of aging populations nor do they provide age-appropriate integrated care services that focuses on maintaining the intrinsic capacity (e.g., physical and mental health functioning) of older persons (WHO, 2015). The heterogeneity among older persons and diversity in their capacities and health needs underscore the importance of a comprehensive, global public-health response. The World Health Organization [WHO] (2015) emphasizes the importance of developing and maintaining high standards of health for older people and building a public health system involving elder-centered medical care and the provision of long-term care.

It is expected that there will be greater demand for long-term care (LTC) homes to accommodate subpopulations of older people who have, or are at high risk of, significant losses in capacity and those with complex health and social needs (United Nations, 2015). However, evidence suggests that most LTC facilities are ill-equipped to care for this growing population and complex care and diverse needs of older people (DeSalvo et al., 2009; Grenade \& Boldy, 2008). Many of LTC facilities fall short of providing quality care, sufficient activities and stimuli, including individualized care and services and recreational support, for residents. Due to lack of meaningful engagement, inactivity and a limited number of social relationships, LTC residents are at high risk for isolation and loneliness (Abbott et al., 2015). It should also be noted, however, that there exists a complex and bi-directional relationship between social isolation and institutionalization. Existing research suggests that social isolation (and loneliness) 
may directly or indirectly lead to institutionalization in many cases (Brock \& O’Sullivan, 1985). In other words, it is likely that some residents of LTC homes are isolated or at-risk of isolation upon moving into the institution. The radical change in the age composition of the current population suggests the need to reform LTC policies to ensure better access to high quality care to improve the quality of life for older adults (Wagner et al., 2012).

\section{Social Isolation in the Context of This Review}

In the scientific literature, social isolation and loneliness are generally considered to be distinct, although closely interrelated, concepts (Grenade \& Boldy, 2008); however, the terms are often wrongly used interchangeably. Although there is a great deal of inconsistency in defining or measuring social isolation (e.g., Holt-Lunstad et al., 2010; Valtorta et al., 2016), the concept is typically defined as an objective measure that is reflected by the number of social contacts or relationships an individual has (Gierveld \& Tilburg, 2006). In contrast, loneliness is defined as a subjective feeling that arises from a lack in the quantity or quality of one's social relationships (Peplau \& Perlman, 1982). Owing to the fact that the two concepts are interrelated, identifying the risk and protective factors specific to each is challenging (Grenade \& Boldy, 2008) as many of the same factors are associated with both. In addition, there continues to be a lack of consistency in the ways in which the concepts are operationalized (Grenade \& Boldy, 2008), which limits the ability to meaningful comparisons between concepts. Therefore, it is important to distinguish between the concepts as one can occur without the other (Perlman, 2004). For the purposes of this review, we will focus mainly on the risk factors for social isolation in older adults in LTC facilities as less is known about the extent of isolation in residential settings. 


\section{Research Gap}

Despite decades of research on social isolation, most studies on the risk factors of social isolation in the older adult population have focused primarily on community dwelling seniors with limited attention on seniors residing in LTC facilities (Grenade \& Boldly, 2008). The lack of research in LTC facilities could be because it is often assumed that older people in LTC settings are less likely to experience social isolation due to its environment, which allows for physical proximity to others through amenities such as communal areas and on-site care (Grenade \& Boldly, 2008; McKee et al., 1999). Given the rise in social isolation among older persons, exacerbated by the recent coronavirus disease 2019 (COVID-19) pandemic, the unique characteristics of the LTC environment, and the paucity of research in this area, this scoping review was designed to address this gap.

\section{The Review}

Aim

The main objective of this scoping review is to present and synthesize the best available evidence on the risk factors contributing to social isolation amongst older adults in LTC settings. Understanding the factors associated with social isolation will contribute to developing targeted interventions to address social isolation and strengthen social engagement among residents, families, and care providers, and ultimately, improve the mental health and quality of life of older people. 


\section{Methods}

Design

The design of this scoping study was based on the seminal work of Arksey and O'Malley (2005) methodology for reviews and enhancements to this work by Levac et al. (2010). As such, this protocol is organized into five stages, expanded upon below.

\section{Stage 1: Identifying the research question(s)}

The first stage, according to Arksey and O'Malley (2005), involves a generalist question and key terms to "generate breadth of coverage". As the aim of this review was to portray an extensive scope of literature pertaining to social isolation. This review was guided by the following interrelated query: What are the risk factors for social isolation among older adults in residential LTC? To address this question, we extracted the risk factors for social isolation as reported in each of the included studies. Key concepts within our research question include 'social isolation', 'older adults', and 'long-term care'.

\section{Stage 2: Identifying relevant literature}

Several preliminary scoping searches were conducted with the intent to gain familiarity with the literature and aid with the identification of keywords, followed by a comprehensive search in five major health bibliographic databases (AGELINE, Cumulative Index to Nursing and Allied Health Literature (CINAHL), MEDLINE, Ovid, PsychInfo). An academic health sciences librarian at the University with years of experience working in the field was consulted to develop the search strategy and execute the searches. Publications included in this review were limited to English language articles published between 1990 and July 2020. The search strategy was developed to identify studies on social isolation for older people, but the strategy was tailored to the risk factors of social isolation among seniors in residential LTC homes. 


\section{Stage 3: Study selection}

The selection of studies for inclusion as well as the exclusion criteria were developed iteratively, as recommended by Levac et al. (2010). Reviewers met throughout the review process to discuss and refine the search strategy, as required. We used Covidence online software (https://www.covidence.org/), the standard platform for Cochrane Reviews, to manage study selection. The study selection process involved three interrelated steps: abstract reviews, fullarticle reviews, and reviewers' examination of reference lists from full articles to identify articles for possible inclusion.

In the initial phase of the search, two of the team members were randomly assigned to review the 768 article titles and abstracts independently. Relevant abstracts were entered into Covidence for each team members to review and indicate "Yes" or "No" depending on whether the abstract met the inclusion criteria. When a discrepancy occurred between reviewers, a separate team member was designated as the arbitrator for discrepancies. In Covidence, once both randomly assigned reviewers marked an abstract as "Yes" for inclusion, the paper automatically moved to the full article review list for the research team to perform a complete review of the articles $(n=69)$. In the second phase of study selection, all four team members were randomly assigned a set of articles for full review (approximately 17 articles per reviewer) using the same inclusion and exclusion criteria. In the third and final phase, we reviewed the article reference lists for additional and/or potentially relevant articles, but none were added. All discrepancies on final article selection and data extraction were arbitrated in a Zoom meeting with all team members. Study selection was reported as per the Preferred Reporting Items for Systematic review and Meta-analysis Protocols (PRISMA-P) guidelines (Moher et al., 2015). The selection process is illustrated in the flow diagram in Figure 1. 


\section{Stage 4: Charting the data}

Data were extracted from the full-text journal articles by one author (SB) using descriptive analytical techniques (Arksey \& O’Malley, 2005; Levac et al., 2010) in ATLAS.ti 8 based on the aforementioned inclusion criteria and cross-checked by the remaining authors (RW, TL, and NT) for accuracy. Data extraction form was iteratively developed by all the authors throughout data charting to ensure the data extracted reflected the theme of the scoping review. For each included article, we charted by author(s), publication details, study aim and design, sample/size, and methodology (selected data are reported in Table 1). 
Table 1. Characteristics of Studies Included in the Scoping Review

\begin{tabular}{|c|c|c|c|c|c|}
\hline Citation & Aim of study & Study design & Sample size & Methodology & Key Findings \\
\hline $\begin{array}{l}\text { Buckley et } \\
\text { al. (2009) }\end{array}$ & $\begin{array}{l}\text { To explore } \\
\text { residents' } \\
\text { relationships } \\
\text { with others }\end{array}$ & $\begin{array}{l}\text { Qualitative } \\
\text { phenomenologic } \\
\text { al design }\end{array}$ & $\begin{array}{l}\mathrm{n}=10 \\
\text { (females } \\
\text { between } \\
71-99 \text { years } \\
\text { old) }\end{array}$ & $\begin{array}{l}\text { Semi- } \\
\text { structured in- } \\
\text { depth } \\
\text { interviews }\end{array}$ & $\begin{array}{ll}\text { - } & \text { Relations between residents were not intimate } \\
\text { - } & \text { Residents replaced certain relationships with other } \\
\text { relationships (e.g., Friends with family) } \\
\text { - } \quad \text { Visitors connected residents with outside world } \\
\text { - } \quad \text { Cognitively intact residents did not want to interact } \\
\text { with cognitively impaired residents } \\
\text { - } \quad \text { Staffs' ability to understand residents' needs } \\
\text { enhanced residents' connectedness. } \\
\text { - } \quad \text { Residents felt cut off from the outside world. }\end{array}$ \\
\hline $\begin{array}{l}\text { Casey et al. } \\
(2015)\end{array}$ & $\begin{array}{l}\text { To describe } \\
\text { nursing home } \\
\text { resident's } \\
\text { perceptions of } \\
\text { their friendship } \\
\text { networks }\end{array}$ & $\begin{array}{l}\text { Multiple social } \\
\text { network analysis } \\
\text { methods (cross- } \\
\text { sectional } \\
\text { interviews, } \\
\text { standardized } \\
\text { assessment, } \\
\text { observation and } \\
\text { network } \\
\text { analyses) } \\
\text { utilized }\end{array}$ & $\begin{array}{l}\mathrm{n}=94 \text { (Older } \\
\text { adults between } \\
\text { the ages of } 63 \text { - } \\
94 \text { years) }\end{array}$ & $\begin{array}{l}\text { Observational } \\
\text { data on } \\
\text { residents' } \\
\text { social } \\
\text { interactions. } \\
\text { Residents } \\
\text { interviewed, } \\
\text { verbal and } \\
\text { nonverbal } \\
\text { responses } \\
\text { recorded }\end{array}$ & $\begin{array}{l}\text { - Approximately } 90 \% \text { of residents took part in at least } \\
\text { one type of structured social activity. } \\
\text { - Residents' had sparse networks with unit coresidents } \\
\text { and cited age and gender as a barrier to forming } \\
\text { friendships with other residents. } \\
\text { - Residents had few nonfamily network members, } \\
\text { leading to risk of social isolation. }\end{array}$ \\
\hline $\begin{array}{l}\text { Cook et al. } \\
(2006)\end{array}$ & $\begin{array}{l}\text { To understand } \\
\text { the difficulties } \\
\text { that residents } \\
\text { with sensory } \\
\text { impairments } \\
\text { face when } \\
\text { interacting with }\end{array}$ & $\begin{array}{l}\text { Study A: } \\
\text { Hermeneutic } \\
\text { inquiry } \\
\text { Study B: } \\
\text { Constructivist } \\
\text { study }\end{array}$ & $\begin{array}{l}\text { Study } n=8 \\
\text { (older adults } \\
\text { between } 52-95 \\
\text { years.) } \\
\text { Study B: } \mathrm{n}= \\
18 \text { (seniors }\end{array}$ & $\begin{array}{l}\text { Study A: } \\
\text { Interviews } \\
\text { Study B: Semi- } \\
\text { structured } \\
\text { interviews, } \\
\text { participant }\end{array}$ & $\begin{array}{l}\text { Being capable of hearing conversations between } \\
\text { others let residents feel as though they were part of } \\
\text { the outside world. Hearing impaired residents miss } \\
\text { out on this. } \\
\text { - When patients accommodated each other's problems, } \\
\text { they became more familiar. } \\
\text { - Residents with sensory impairments had difficulty }\end{array}$ \\
\hline
\end{tabular}




$\begin{array}{ll}\text { Grenade et } & \text { Identified } \\ \text { al. (2008) } & \text { research gaps on } \\ & \text { social isolation } \\ & \text { in residential } \\ & \text { homes }\end{array}$

Kortes-

To examine

Miller et al. LGBTQ+ adults'

(2018) perspectives on their future in

LTCs others

$70+$ years)

N/A

N/A

N/A

observation, and resident focus group interviews

homes

\section{Qualitative \\ analysis - Focus \\ groups}

$\mathrm{n}=23$ (Older Focus groups

adults aged 57- lasted $1.5 \mathrm{hrs}$.

78)

Audio

recordings and

transcriptions

kept from the

focus groups

Systematic

$\begin{array}{ll}\text { Two-stage } & \mathrm{n}=6 \\ \text { narrative review } & \text { publications }\end{array}$

narrative review publications approach was

employed recognizing others that they had previously met, their lack of acknowledgment was sometimes viewed as rudeness.

- In the community, a large proportion of older adults experience some degree of loneliness with sociodemographic, health, and life events acting as risk factors

- Little is known about loneliness and social isolation in nursing homes, some evidence suggests that residents still experience loneliness

- In residential care, poor health, frailty, diminished cognitive capacity, and dependency act as risk factors for social isolation

- In residential care, potential interventions include organised activities and events that help residents stay connected with the wider community

- Participants were concerned about stigmatization and discrimination.

- Participants were worried about being void of social support, losing autonomy and being dependent on care providers.

- Feared that other residents would be judgemental, and that the environment might not be supportive of their identity.

- Environmental factors and cognitive impairment impeded communication for those with hearing loss.

- Hearing loss limited residents' abilities to participate in social activities.

- LTC did not have adequate onsite services and

\section{LTCs}




$\begin{array}{llll}\begin{array}{l}\text { Parmenter } \\ \text { et al. } \\ (2012)\end{array} & \begin{array}{l}\text { To identify } \\ \text { determinants of } \\ \text { rural nursing } \\ \text { homes visits }\end{array} & \text { Survey } & \begin{array}{l}\mathrm{n}=257 \\ \text { (Seniors } 6 \\ \text { years) }\end{array} \\ \begin{array}{l}\text { Webber et } \\ \text { al. (2014) }\end{array} & \begin{array}{l}\text { To explore the } \\ \text { experience of } \\ \text { older adults with } \\ \text { intellectual } \\ \text { disabilities in }\end{array} & \begin{array}{l}\text { Dimensional } \\ \text { analysis }\end{array} & \begin{array}{l}\mathrm{n}=10(7 \\ \text { males, } 3 \\ \text { females })\end{array} \\ & & \\ & & \end{array}$

Structured

telephone

surveys

Group home staff, LTC

staff and

family were

interviewed

about residents assisted listening devices.

- Care staff received little information and training on ways to improve communication for hearing impaired residents but still tried to enhance communication.

- Longer amount of time spent living in a LTC was associated with a decline in the number of visitors.

- Common barriers to frequent visiting included time, distance and transport problems.

- Other residents were uncomfortable with residents with intellectual disabilities and avoided them.

- Residents with intellectual disabilities preferred interacting with staff to other residents and experienced a disconnection from past relationships.

- Intellectually disabled residents' health improved. 


\section{Stage 5: Collating, summarizing and reporting the results}

The final stage involves analysis of the data charted, reporting of results, and determining the implications of findings, which was a collaborative process among all authors. The results are reported as a narrative summary of study findings. We begin by describing the type of studies included, followed by a thematic analysis, and conclude with a discussion of the implications of our analysis.

\section{Results}

The electronic searches conducted in July 2020 yielded 1,798 potentially relevant citations. After deduplication and relevance screening, 177 citations met the eligibility criteria based on title and abstract and the corresponding full-text articles were procured for review (Phase 1 screening). The abstracts underwent title review followed by detailed abstract review, after which, 69 were selected for full-text review (Phase 2 screening). After data characterization of the full-text articles, eight scoping reviews remained and were included in the analysis (see Figure 1). 


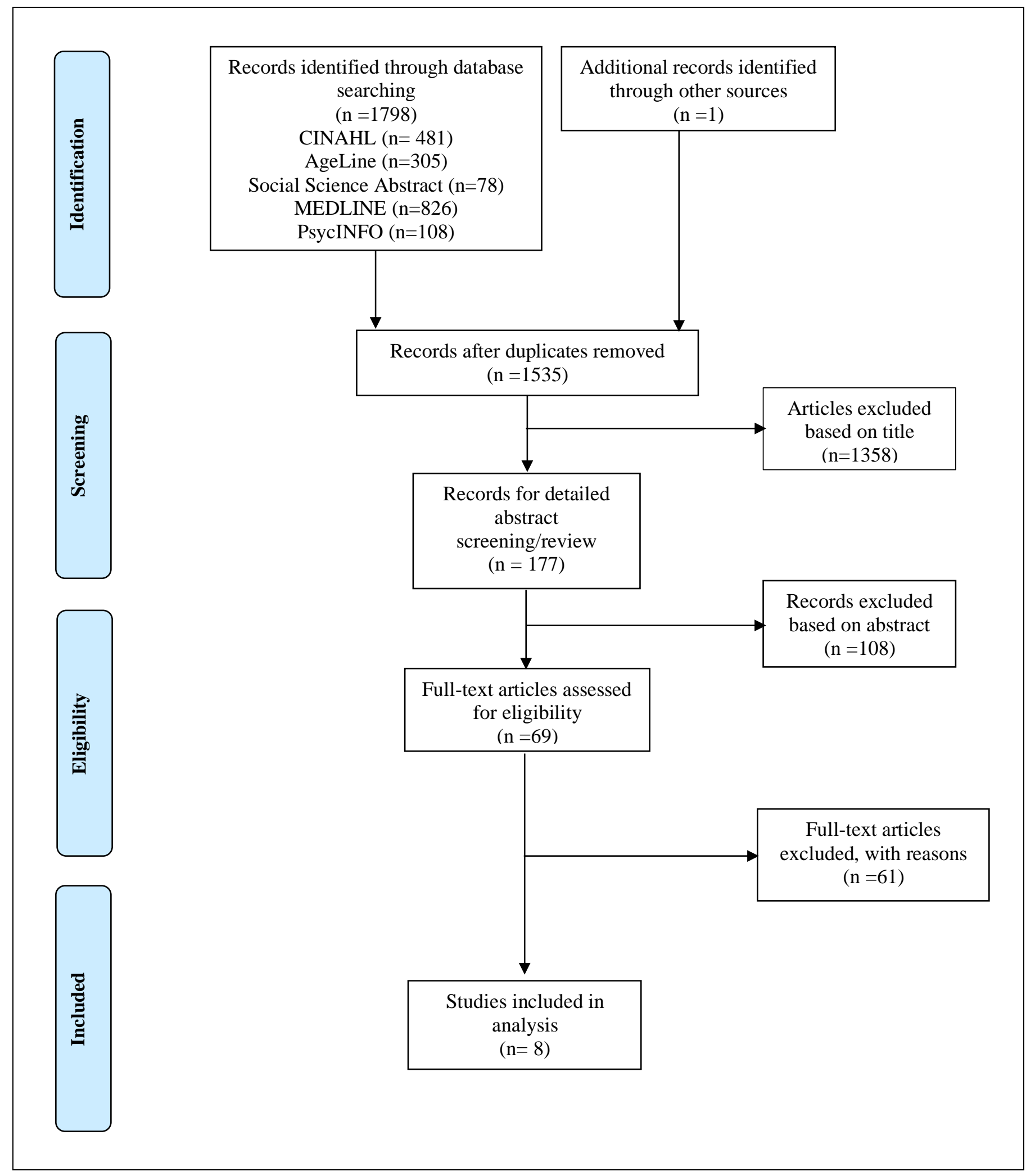

Figure 1. PRISMA chart. Source. Moher D., Liberati A., Tetzlaff J., Altman D. G., \& The PRISMA Group (2009). Preferred reporting items for systematic reviews and meta-analyses: The PRISMA statement. PLoS Med, 6(7), Article. e1000097. doi:10.1371/journal.pmed1000097. 
Quality assessment: Due to the limited number of relevant articles, we did not assess the methodological quality of individual studies as it is not a priority in scoping reviews or part of the scoping review methodology (Peters et al., 2017). However, some claim formal assessment should be incorporated in the methodology (Daudt et al., 2013), as assessing study quality will enable us to address not only quantitative, but also qualitative gaps in the literature (Levec et al., 2010). Being aware of the Arksey and O’Malley’s framework's inability to provide for an assessment of the quality of the literature (Daudt et al., 2013), our research team is conducting this scoping review as the basis for our next stage of research and will take measures to address this concern in future studies, including using validated instruments.

Thematic analysis: Data were analyzed from an extensive assessment of the eight studies and categorized into three broad themes: 1) Individual factors (issues at the level of the individual patient that predispose residents to isolation), 2) Systems factors (factors stemming from the healthcare system/LTC and its structure), and 3) Structural factors (factors that are embedded within and systematically produced by historical, political, social or economic structures).

Theme 1-Individual factors: Individual factors relate to issues at the level of the individual resident that predisposes them to social isolation, including communication barriers, and cognitive impairment. Inability to effectively communicate one's thought was noted as a key risk factor for experiencing and becoming socially isolated (Casey et al. 2016; Cook et al., 2006; Grenade \& Boldy, 2008; Ludlow et al., 2018). Six of the eight publications reported the effects of poor communication between fellow residents and/or healthcare providers, as a barrier to residents' engagement and participation in social activities. Communication breakdown as a result of sensory deficits including hearing loss was noted in various degrees in all of the eight 
articles reviewed. Grenade and Boldy (2008) reported "loneliness and/or isolation to be associated with sensory impairments (e.g., hearing loss) and physical disabilities” (p. 471). Ludlow et al. (2018) noted similar concerns, but this time focused on the physical environment in the LTC homes and concluded that the environment in the home often makes it challenging to those with sensory deficits and can create communication breakdown for residents experiencing hearing loss. Background noise from the environment and surroundings can reduce residents' abilities to hear others and engage in conversation and "participation in the life of the aged care facilities" (Ludlow et al., 2018, p. 300). The inability to effectively communicate thoughts left many residents struggling to make meaningful connections with fellow residents, depriving them of opportunities to make meaningful friendships. The concept of friendship and positive network within the care home was especially important to residents. Casey et al. (2016) reported that impaired communication ability to approach or avoid others decreased residents' social functioning and ability to engage in casual conversations and have positive interactions that may lead to relationship building.

Another individual factor reported in almost all of the articles was the role of cognition in social engagement. Cognitive impairment was commonly reported as a factor resulting in social isolation among residential long-term care residents, especially for residents living with dementia and Alzheimer's disease. Studies have shown longitudinal associations between cognitive decline and social isolation and vice versa (Evans et al., 2019; Read et al., 2020; Thomas, 2011). Impairment in cognition intensify communication difficulties for residents especially among those with hearing loss as the effects of mishearing information and the inability to fully comprehend became a source of confusion. In our review, Ludlow et al. (2018) reported that "residents with dementia had a higher risk of communication breakdown; cognitive and language 
difficulties coupled with hearing loss affected residents' ability to maintain conversation" (p. 299). These statements were frequently echoed in other papers.

Theme 2 - Systems factors: These are factors stemming from the health care/LTC facility and its structure, rather than from an individual or interaction between individuals. Systems factors include the location of the LTC facility and availability of staff, the types of services provided including individualized care and autonomy of residents, and the interaction between various aspects of the healthcare system. Four of the eight studies supporting theme 2 reported the geographical constraints and challenges of maintaining friendships outside of the LTC facility. The geographic location of the LTC facility, especially those in rural or remote communities presented unique challenges for residents to maintain closely connect with their friends and family, travel to and from LTC to visit friends and/or have frequent visitations, which often resulted in residents experiencing social isolation. Another theme that was identified was the lack of integration between LTC and broader community/society. In four of the articles, residents reported losing touch with their existing network after moving into LTC and felt disconnected from the broader community. In a study of Irish LTC residents, Buckley and McCarthy (2009) found that "unfortunately, with admission to a long-term care facility, older adults experience difficulty maintaining relationships with friends and feel they have little to exchange with friends who reside in the outside world" (p. 390). The lack of contact with the outside world is concerning because it increases the risk of isolation, loneliness, and associated ill health effects. In addition to the already shrinking social network, Buckley and McCarthy (2009) also reported that six out of 10 residents found it difficult to make friends with other residents even after being in the LTC facility for a number of years, and that they relied on 
visitors in helping them keep up to date on social events occurring in the family and within the community. Another article reported that:

"Most residents would also experience some form of loss following a move into residential care — for example as a result of having to leave their home, family and friends (and pets in many cases), local communities and previous life-styles." (Grenade \& Boldy, 2008, p. 472)

New residents are often emotionally intertwined in the relationship they had with friends, families and relatives, and that staff and resident relationships become particularly important and crucial to residents' quality of life. Family members also expressed concern about the disconnection from past relationships (Webber et al., 2014). Buckley and McCarthy (2009) explored the perceptions of social connectedness in LTC and reported that residents, "expressed feelings of "homesickness" and felt they were more connected to their home and what went on there than they were to the long-term care facility. A dwindling pool of friends and relatives due to old age or illness affected the number of social contacts the residents had." (p. 393)

Shortage of nursing and other health care staff in LTC facilities was identified as a contributing factor to social isolation and decrease in quality of care/life. The interaction and conversations residents have with staff members gave them a feeling of being equal in the relationship, provided a sense of belonging and authenticated the caring relationship (Buckley \& McCarthy, 2009). Attitudes and actions of carers either facilitated or hindered residents' ability to socially connect with other residents. Buckley and McCarthy (2009) found that residents felt, "having 
someone who listened to them and with whom they felt at ease promoted communication" (p. 393). Two of the eight studies (Grenade \& Boldy, 2008; Kortes-Miller et al., 2018) raised the issue of lack of autonomy including dependence on staff and losing ability to make choices as having potentially negative impact on residents' quality of life as it contributed to their experience of isolation in LTC homes. Kortes-Miller et al. (2018) shared similar concerns that when residents who are otherwise able to engage in their own activities of daily living loss their autonomy and become dependent on care providers, and to a greater extent the healthcare system, "they anticipate that the aging process will strip away their capacity for decisionmaking” (p. 209). In doing so, residents become increasingly vulnerable. The dependence on the health system and providers can negatively affect the residents' social supports (e.g., family, friends, partners, etc.), and as such, "those who are alone are particularly at risk of having their own quality of life spiral downward" (p. 217).

Theme 3 - Structural factors: Structural factors refer to influences that are embedded within and systematically produced by the historical, social, political, and economic structure of a society (McGibbon, 2016; Navarro, 2007). The socioeconomic and historical conditions of LTC facilities are structures designed by the governments/funding agencies, which to greater extent, contribute to inequities in access to health care and resources for the older adult. Structural factors also include the social and physical characteristics of the LTC home environment (e.g., shared living space, provision of nursing and personal care, social and recreational programme etc.), as well as the residents in the facility (e.g., mostly older people with complex healthcare needs) which all play an important role in the well-being of the older adult. In this review, we found that when LTC residents have decreased autonomy in outdoor 
participation and increased dependence on staff, they become increasingly isolated, which negatively impacts their quality of life. One participant was quoted saying that:

"Moving into an institutional environment, with its rules and routines, where one is dependent on others for care and support, can also have a major impact on a person's ability to retain a sense of autonomy and control over their lives and/or to express their individuality. This may lead to reduced self-esteem, loss of identity and depression." (Grenade \& Boldy, p. 472)

Residents with reduced social networks (e.g., size, composition and quality of relationships) become increasingly dependent on care staff in the LTC facility, which places them at greater risk of social isolation. Research has shown clear links between socioeconomic status (e.g., poverty, limited resources, and network) and social isolation (Kearns et al., 2015). Older people of lower socioeconomic status are more vulnerable to social isolation due to living situations such as living in an unsafe neighbourhood, or limited financial means (Andersson, 1998; Kearns et al., 2015). And although LTC residents may have safer living conditions, they are not immune as those with limited means/resources can experience similar stressors and concerns as their counterparts in the community.

Our results showed that lack of opportunities for social engagement and building new relationships contributed significantly to social isolation among older adults in LTC homes. Buckley and McCarthy (2009) reported that cognitively intact residents "felt 'different' from residents with diminished mental capacity. If these residents were noisy or disruptive, it further supported the feeling of disconnection" (Buckley \& McCarthy, 2009, p. 393). Similar concern was expressed in the study by Casey et al. (2016) on nursing home residents' perceptions of their 
friendship networks. The authors reported that, "residents [also] indicated uncertainty and ambiguity in close relationships, describing friendship as "difficult" in the nursing home context and noting barriers to friendship such as language and the fact that others "have dementia" (Casey et al., 2016, p. 860). Our results highlight the struggles that both cognitively intact residents and also those who are living with dementia and other mental health conditions face and their unique risk for becoming socially isolated.

Discrimination was identified as another risk factor for social isolation among LTC residents. Our review showed that residents who experience discrimination from LTC staff/care providers and healthcare system are more likely to be isolated. In particular, aging LGBTQ+ individuals reported experiencing stigma and having unique fears, which are often related to personal safety and discrimination. One participant reported that:

"Participant who encountered issues of heterosexist assumptions with a health care practitioner described similar fears. However, this participant also recognized that they may be experiencing even greater discrimination within health systems due to the layering of multiple marginalized social positions." (Kortes-Miller et al., 2018, p. 215)

Older LGBTQ+ adults were stressed because of fear of being assessed LTC environments for risks of discrimination and rejection. The residents reported fear of being "forced to silence parts of their identities in order to protect themselves and appease others" (Kortes-Miller et al., 2018, p. 214). 


\section{Discussion}

This paper presents the results of a scoping review investigating risk factors for social isolation among older adults living in LTC homes. As mentioned, this area of research represents a significant gap in the existing literature on aging and isolation. The bulk of existing research on late life social isolation has focused largely on the experiences of community-dwelling older people (Grenade \& Boldy, 2008). Consequently, the results presented in this paper provide a much-needed analysis of the current state of scholarly literature regarding social isolation in LTC. Although very few articles met the inclusion criteria for this scoping review (see Methods), the included eight papers formed a rich dataset from which to identify several insights. Together these insights underscore important implications for both practice and research on social isolation in later life while simultaneously raising critical considerations about LTC more broadly.

The first insight pertains to individual-level risk factors for social isolation. The articles included in this review described several individual-level risk factors of note for older people living in LTC homes including communication barriers, sensory impairment, and cognitive impairment. Within the broader social isolation literature there exists a wealth of knowledge linking factors at the level of the individual to increased risk of social isolation. However, this literature has tended to emphasize the risk associated with multiple comorbidities, mental health concerns, and the death of loved ones, such as one's spouse (Cotterell et al., 2018; Nicholson, 2012). Fewer studies have investigated the role of communication barriers and cognitive impairment as risk factors. With respect to sensory deficits, hearing loss and the associated communication challenges have been linked to increased risk of social isolation among older people (Mick et al., 2014), Likewise, poor self-reported vision is a significant predictor of social 
isolation (Coyle et al., 2017). On the other hand, evidence linking cognitive impairment and isolation risk is mixed (Havens et al., 2004), with studies more often investigating cognitive impairment as an outcome of social isolation rather than a predictor (Holwerda et al., 2014; Lara et al., 2019). Overall, these findings complement and build upon the existing literature by providing preliminary evidence that several individual level risk factors remain relevant for those who live in LTC facilities. However, it is unclear if and how these risk factors may interact with other risk factors differently within the LTC context. It is our recommendation that future research investigate the potential for these individual-level risk factors to differentially shape risk of isolation among those living in LTC.

The second insight pertains to risk factors for social isolation that exist beyond the individual. Analyses revealed that these risk factors fell into two categories: systems factors and structural factors. As with the individual-level risk factors, our findings mirror existing research, but also bring possible LTC-specific risk factors to light. Studies in this review emphasized the potential for aspects of the LTC environment and healthcare system to shape risk of isolation among residents (Buckley \& McCarthy, 2009; Grenade \& Boldy, 2008; Kortes-Miller et al., 2018). These potential contributing factors included reduced autonomy/increased dependence, and the disconnect from existing social connections in the community (e.g., family members or friends not living in the LTC). The described loss of independence is somewhat unique to those living in LTC homes in that community-dwelling older people are unlikely to experience such stripping of autonomy due to institutional procedures and policies. Similarly, while moving to any new home may bring about disconnect from contacts and network members, transitioning into long-term care may be particularly isolating due to factors such as geographical location, lack of integration with the wider community, and visiting policies. The preliminary evidence 
identified in this review suggests a need for research examining these risks and other characteristics of the systems within LTC that may contribute to the isolation of residents.

At the structural level, studies in this review identified that few opportunities for connection and discrimination were both important factors in shaping perceived isolation risk, particularly for residents of minority groups and those who otherwise felt different from others (Buckley \& McCarthy, 2009; Kortes-Miller et al., 2018). These findings are supported by existing research. While a large portion of the gerontological literature has taken a highly individualized approach to social isolation (Weldrick \& Grenier, 2018), studies in recent years have increasingly acknowledged structural and societal factors. In doing so, researchers have begun to uncover mechanisms through which older people may come to be socially isolated due to circumstances beyond themselves and beyond their control. For example, a large study of urban-dwelling older people found that few opportunities for connection, a lack of social cohesion, and age-segregated living all contributed to social isolation risk (Buffel et al., 2015). Additionally, there is evidence to suggest that discrimination and marginalization may contribute to the social isolation, particularly among ethnic minorities, although additional research is warranted to determine the extent to which this may be the case, and under what conditions (Visser \& El Fakiri, 2016). The findings of this review are consistent with this work, but also highlight the need for intervention strategies that tackle discrimination and other structural contributors.

These systems- and structural-level findings are especially noteworthy given that several are unique to those living in institutional environments or are experienced differently within the context of LTC. In finding that certain relevant risk factors for social isolation stem from operational aspects of LTC systems and environments, this review contributes to a wider 
narrative shift within the social isolation literature whereby systems and structures increasingly come into focus and under scrutiny. Based on these results, it is recommended that future research critically examine the impacts of LTC systems and operations in contributing to the isolation of residents. It is also recommended that this work emphasize the experiences and voices of residents of minority groups and other residents who may be more likely to experience discrimination. As demand for LTC beds continues to increase (World Health Organization, 2015), this work will become all the more crucial. Investigations into these important systems factors will also begin to address the concerning realities of many LTC facilities that have come to light during the COVID-19 global pandemic (Inzitari et al., 2020).

In addition to contributions to the scholarly literature on social isolation risk, the findings of this scoping review also have practical implications for LTCs and those providing care within LTC. Broadly speaking, the individual- and structural-level themes identified in this review complement the existing evidence on isolation risk. However, several of these findings indicate that there are several risk factors that are unique to those residing in LTCs, such as the loss of independence and social network connections as a result of moving into an institution as described by several studies in this review (Grenade \& Boldy, 2008; Buckley \& McCarthy, 2009). The discovery of risk factors unique to those living in LTC institutions brings into question the current assessment criteria and tools used to identify those at-risk of isolation. Given these findings, it is likely that assessment criteria will require optimization to more accurately monitor and evaluate social isolation among this population. There currently exist many scales used to measure risk and social isolation, and reliability studies have been conducted to aggregate and synthesize various indicators employed across these scales (Cornwell \& Waite, 2009). These scales have not been tested for reliability within long-term care populations, 
however. Indeed, many of the scales currently used by practitioners include elements of social disconnectedness, often defined in terms of physical separation from other people (Cornwell \& Waite, 2009). As older people living in LTC are in essence surrounded by other people, scales that employ this type of criteria will be biased and theoretically less sensitive to identifying isolation among these individuals. Together, these developments provide strong justification for the development of LTC-specific assessment criteria. In a similar vein, the findings from this review suggest a need to revisit current approaches to isolation interventions and prevention strategies within LTC settings that address these unique contributing factors.

The results of the scoping review also raise several critical questions about the planning and operation of modern LTC homes. By and large, the studies included in this review paint a picture of long-term care institutions that is less than favourable. Particularly with respect to structural and systems-level risks, studies indicated that the social ecosystems within LTCs are not always conducive to strong social integration among residents. Findings underscore problematic patterns related to discrimination and stigmatization, as well as a myriad of social barriers experienced by those with sensory impairments. This theme justifies a re-envisioning of LTC practices currently in place. Specifically, policymakers and other stakeholders are urged to consider how LTC facilities may be better oriented to promote social connection within the institutional environment and to explore means of improving the integration of LTC institutions themselves within the wider community.

Our scoping review was limited by the sparse existence of work on social isolation within the contexts of LTC. While conducting the database searches and subsequent hand searching, the research team identified dozens of articles mentioning social isolation within long-term care homes, however this was seldom framed as a focus within these papers. While this dearth of 
evidence led to a small $(n=8)$ number of papers meeting our inclusion criteria, it also provides a strong rationale for this review. The relatively limited availability of evidence in this domain indicates that there is a great need for additional research.

\section{Conclusion}

This scoping review maps the limited literature on risks for social isolation among older people living in long-term care facilities. The findings address a significant knowledge gap and provide a timely overview of the documented risk factors for this population. It remains clear, however, that relatively little is known about the experiences of older, socially isolated people in LTC settings and other residential aged care facilities. Altogether, it is recommended that future research should consider further investigation into these possible risk factors and explore methods of intervening/preventing isolation within LTC. As population aging continues and demand for LTC trends upwards, work in this area will become increasingly critical.

\section{Declarations of Conflicting Interests}

The authors declare no conflict of interests with respects to the review, authorship, submission and/or publication of this article.

\section{Ethical Approval}

As this is a review article ethics was not required for this study. 


\section{References}

Abbott, K. M., Bettger, J. P., Hampton, K. N., \& Kohler, H. P. (2015). The feasibility of measuring social networks among older adults in assisted living and dementia special care units. Dementia, 14(2), 199-219.

Ajrouch, K. J., Antonucci, T. C., \& Janevic, M. R. (2001). Social networks among Blacks and Whites: The interaction between race and age. The Journals of Gerontology: Series B: Psychological Sciences and Social Sciences, 56(2), S112-S118.

Andersson, L. (1998). Loneliness research and interventions: A review of the literature. Aging \& Mental Health, 2(4), 264-274. https://doi.org/10.1080/13607869856506

Arksey, H., \& O’Malley, L. (2005). Scoping studies: Towards a methodological framework. International Journal of Social Research Methodology, 8(1), 19-32. https://doi.org/10.1080/1364557032000119616

British Columbia Ministry of Health. (2004). Social isolation among seniors: An emerging issue. Report of the British Columbia Ministry of Health. March, 46. http://www.health.gov.bc.ca/library/publications/year/2004/Social_Isolation_Among_Senior s.pdf

Brock, A. M., \& O'Sullivan, P. (1985). A study to determine what variables predict institutionalization of elderly people. Journal of Advanced Nursing, 10(6), 533-537.

Buckley, C., \& McCarthy, G. (2009). An exploration of social connectedness as perceived by older adults in a long-term care setting in Ireland. Geriatric Nursing (New York, N.Y.), 30(6), 390-396. https://doi.org/10.1016/j.gerinurse.2009.09.001

Buffel, T., Rémillard-Boilard, S., \& Phillipson, C. (2015). Social Isolation Among Older People in Urban Areas. http://www.micra.manchester.ac.uk/connect/news/headline-430995-en.htm

Casey, A.-N. S., Low, L.-F., Jeon, Y.-H., \& Brodaty, H. (2016). Residents perceptions of friendship and positive social networks within a nursing home. The Gerontologist, 56(5), 855-867. https://doi.org/10.1093/geront/gnv146

Cattan, M., White, M., Bond, J., \& Learmouth, A. (2005). Preventing social isolation and loneliness among older people: A systematic review of health promotion interventions. Ageing \& Society, 25(1), 41-67.

Cloutier-Fisher, D., Kobayashi, K., \& Smith, A. (2011). The subjective dimension of social isolation: A qualitative investigation of older adults' experiences in small social support 
networks. Journal of Aging Studies, 25(4), 407-414.

https://doi.org/10.1016/j.jaging.2011.03.012

Consedine, N., Magai, C., \& Conway, F. (2004). Predicting ethnic variation in adaptation to later life: Styles of socioemotional functioning and constrained heterotypy. Journal of CrossCultural Gerontology, 19(2), 95-129.

Cook, G., Brown-Wilson, C., \& Forte, D. (2006). The impact of sensory impairment on social interaction between residents in care homes. International Journal of Older People Nursing, 1(4), 216-224. https://doi.org/10.1111/j.1748-3743.2006.00034.x

Cornwell, E. Y., \& Waite, L. J. (2009). Measuring social isolation among older adults using multiple indicators from the NSHAP study. The Journals of Gerontology Series B:

Psychological Sciences and Social Sciences, 64B(Supplement 1), i38-i46. https://doi.org/10.1093/geronb/gbp037

Cotterell, N., Buffel, T., \& Phillipson, C. (2018). Preventing social isolation in older people. Maturitas, 113(April), 80-84. https://doi.org/10.1016/j.maturitas.2018.04.014

Courtin, E., \& Knapp, M. (2017). Social isolation, loneliness and health in old age: A scoping review. Health \& Social Care in the Community, 25(3), 799-812. https://doi.org/10.1111/hsc.12311

Coyle, C. E., Steinman, B. A., \& Chen, J. (2017). Visual acuity and self-reported vision status: Their associations with social isolation in older adults. Journal of Aging and Health, 29(1), 128-148. https://doi.org/10.1177/0898264315624909

Cudjoe, T. K. M., Roth, D. L., Szanton, S. L., Wolff, J. L., Boyd, C. M., \& Thorpe, R. J. (2020). The epidemiology of social isolation: National health and aging trends study. The Journals of Gerontology: Series B, 75(1), 107-113. https://doi.org/10.1093/geronb/gby037

Daudt, H. M., van Mossel, C., \& Scott, S. J. (2013). Enhancing the scoping study methodology: A large, inter-professional team's experience with Arksey and O'Malley's framework. BMC Medical Research Methodology, 13(1), 48. https://doi.org/10.1186/1471-2288-13-48

DeSalvo, K. B., Jones, T. M., Peabody, J., McDonald, J., Fihn, S., Fan, V., He, J., \& Muntner, P. (2009). Health care expenditure prediction with a single item, self-rated health measure. Medical Care, 47(4), 440-447. https://doi.org/10.1097/MLR.0b013e318190b716 
Evans, I., Martyr, A., Collins, R., Brayne, C., \& Clare, L. (2019). Social isolation and cognitive function in later life: A systematic review and meta-analysis. Journal of Alzheimer's disease: $J A D, 70(\mathrm{~s} 1)$, S119-S144. https://doi.org/10.3233/JAD-180501

Gierveld, J. D. J., \& Tilburg, T. V. (2006). A 6-Item scale for overall, emotional, and social loneliness: confirmatory tests on survey data. Research on Aging . https://doi.org/10.1177/0164027506289723

Grenade, L., \& Boldy, D. (2008). Social isolation and loneliness among older people: Issues and future challenges in community and residential settings. Australian Health Review: A Publication of the Australian Hospital Association, 32(3), 468-478.

https://doi.org/10.1071/ah080468

Havens, B., Hall, M., Sylvestre, G., \& Jivan, T. (2004). Social isolation and loneliness: Differences between older rural and urban Manitobans. Canadian Journal on Aging / La Revue Canadienne Du Vieillissement, 23(2), 129-140. https://doi.org/10.1353/cja.2004.0022

Heffner, K. L., Waring, M. E., Roberts, M. B., Eaton, C. B., \& Gramling, R. (2011). Social isolation, C-reactive protein, and coronary heart disease mortality among communitydwelling adults. Social Science \& Medicine, 72(9), 1482-1488.

https://doi.org/10.1016/j.socscimed.2011.03.016

Holt-Lunstad, J., Smith, T. B., \& Layton, J. B. (2010). Social relationships and mortality risk: A meta-analytic Review. PLOS Medicine, 7(7), e1000316.

https://doi.org/10.1371/journal.pmed.1000316

Holwerda, T. J., Deeg, D. J. H., Beekman, A. T. F., Tilburg, T. G. van, Stek, M. L., Jonker, C., \& Schoevers, R. A. (2014). Feelings of loneliness, but not social isolation, predict dementia onset: Results from the Amsterdam study of the elderly (AMSTEL). Journal of Neurology, Neurosurgery \& Psychiatry, 85(2), 135-142. https://doi.org/10.1136/jnnp-2012-302755

Ibrahim, R., Abolfathi Momtaz, Y., \& Hamid, T. A. (2013). Social isolation in older Malaysians: Prevalence and risk factors. Psychogeriatrics: The Official Journal of the Japanese Psychogeriatric Society, 13(2), 71-79. https://doi.org/10.1111/psyg.12000

Inzitari, M., Risco, E., Cesari, M., Buurman, B. M., Kuluski, K., Davey, V., Bennett, L., Varela, J., \& Prvu Bettger, J. (2020). Nursing homes and long term care after COVID-19: A new ERA? The Journal of Nutrition, Health \& Aging. https://doi.org/10.1007/s12603-020-1447-8 
Kearns, A., Whitley, E., Tannahill, C., \& Ellaway, A. (2015). Loneliness, social relations and health and wellbeing in deprived communities. Psychology, Health \& Medicine, 20(3), 332344. https://doi.org/10.1080/13548506.2014.940354

Kortes-Miller, K., Boulé, J., Wilson, K., \& Stinchcombe, A. (2018). Dying in long-term care: Perspectives from sexual and gender minority older adults about their fears and hopes for end of life. Journal of Social Work in End-of-Life \& Palliative Care, 14(2/3), 209-224. cin20. https://doi.org/10.1080/15524256.2018.1487364

Lara, E., Caballero, F. F., Rico-Uribe, L. A., Olaya, B., Haro, J. M., Ayuso-Mateos, J. L., \& Miret, M. (2019). Are loneliness and social isolation associated with cognitive decline? International Journal of Geriatric Psychiatry, 34(11), 1613-1622. https://doi.org/10.1002/gps.5174

Lehning, A. J., Scharlach, A. E., \& Dal Santo, T. S. (2010). A web-based approach for helping communities become more "Aging Friendly”. Journal of Applied Gerontology, 29(4) 415433.

Levac, D., Colquhoun, H., \& O’Brien, K. K. (2010). Scoping studies: Advancing the methodology. Implementation Science, 5(1), 69. https://doi.org/10.1186/1748-5908-5-69

Ludlow, K., Mumford, V., Makeham, M., Braithwaite, J., \& Greenfield, D. (2018). The effects of hearing loss on person-centred care in residential aged care: A narrative review. Geriatric Nursing, 39(3), 296-302. cin20. https://doi.org/10.1016/j.gerinurse.2017.10.013

McGibbon, E. (2016). Oppressions and access to health care: Deepening the conversation. In: D. Raphael (Ed.), Social determinants of health: Canadian perspectives, third ed (pp. 491520). Canadian Scholars' Press Inc.

Mckee, K. J., Harrison, G., \& Lee, K. (1999). Activity, friendships and wellbeing in residential settings for older people. Aging \& Mental Health, 3(2), 143-152. https://doi.org/10.1080/13607869956307

Mick, P., Kawachi, I., \& Lin, F. R. (2014). The association between hearing loss and social isolation in older adults. Otolaryngology--Head and Neck Surgery: Official Journal of American Academy of Otolaryngology-Head and Neck Surgery, 150(3), 378-384. https://doi.org/10.1177/0194599813518021

Moher, D., Shamseer, L., Clarke, M., Ghersi, D., Liberati, A., Petticrew, M., Shekelle, P., Stewart, L. A., \& PRISMA-P Group. (2015). Preferred reporting items for systematic review 
and meta-analysis protocols (PRISMA-P) 2015 statement. Systematic Reviews, 4(1), 1. https://doi.org/10.1186/2046-4053-4-1

Murthy, V. (2017, September 26). Work and the loneliness epidemic. Harvard Business Review. https://hbr.org/2017/09/work-and-the-loneliness-epidemic

National Seniors Council. (2014). Report on the Social Isolation of Seniors 2013-2014 (Issue October). https://www.canada.ca/content/dam/nsc-cna/documents/pdf/policy-and-programdevelopment/publications-reports/2014/Report_on_the_Social_Isolation_of_Seniors.pdf

Navarro, V. (2007). What is a national health policy? International Journal of Health Services, 37(1), 1-14. https://doi.org/10.2190/H454-7326-6034-1T25

Nicholson, N. R. (2012). A review of social isolation: An important but underassessed condition in older adults. Journal of Primary Prevention, 33(2-3), 137-152. https://doi.org/10.1007/s10935-012-0271-2

Parmenter, G., Cruickshank, M., \& Hussain, R. (2012). The social lives of rural Australian nursing home residents. Ageing \& Society, 32(2), 329-353. cin20. https://doi.org/10.1017/S0144686X11000304

Peplau, L. A., \& Perlman, D. (1982). Loneliness: A sourcebook of current theory, research and therapy. Wiley.

Perlman, D. (2004). European and Canadian studies of loneliness among seniors. Canadian Journal on Aging / La Revue Canadienne Du Vieillissement, 23(2), 181-188. https://doi.org/10.1353/cja.2004.0025

Peterson, J., Pearce, P. F., Ferguson, L. A., \& Langford, C. A. (2017). Understanding scoping reviews: Definition, purpose, and process. Journal of the American Association of Nurse Practitioners, 29(1), 12-16. https://doi.org/10.1002/2327-6924.12380

Portacolone, E., Perissinotto, C., Yeh, J. C., \& Greysen, S. R. (2018). "I feel trapped": The tension between personal and structural factors of social isolation and the desire for social integration among older residents of a high-crime neighborhood. Gerontologist, 58(1), 7988. https://doi.org/10.1093/geront/gnw268

Read, S., Comas-Herrera, A., \& Grundy, E. (2020). Social isolation and memory decline in laterlife. The Journals of Gerontology. Series B, Psychological Sciences and Social Sciences, 75(2), 367-376. https://doi.org/10.1093/geronb/gbz152 
Santini, Z. I., Jose, P. E., York Cornwell, E., Koyanagi, A., Nielsen, L., Hinrichsen, C., Meilstrup, C., Madsen, K. R., \& Koushede, V. (2020). Social disconnectedness, perceived isolation, and symptoms of depression and anxiety among older Americans (NSHAP): A longitudinal mediation analysis. The Lancet Public Health, 5(1), e62-e70. https://doi.org/10.1016/S2468-2667(19)30230-0

Shor, E., Roelfs, D. J., \& Yogev, T. (2013). The strength of family ties: A meta-analysis and meta-regression of self-reported social support and mortality. Social Networks, 35(4), 626638. https://doi.org/10.1016/j.socnet.2013.08.004

Steptoe, A., Shankar, A., Demakakos, P., \& Wardle, J. (2013). Social isolation, loneliness, and all-cause mortality in older men and women. Proceedings of the National Academy of Sciences, 110(15), 5797-5801. https://doi.org/10.1073/pnas.1219686110

Thomas, P. A. (2011). Gender, social engagement, and limitations in late life. Social Science \& Medicine (1982), 73(9), 1428-1435. https://doi.org/10.1016/j.socscimed.2011.07.035

Uchino, B. N. (2006). Social support and health: A review of physiological processes potentially underlying links to disease outcomes. Journal of Behavioral Medicine, 29(4), 377-387. https://doi.org/10.1007/s10865-006-9056-5

United Nations. (2015). World population ageing 2015. https://www.un.org/en/development/desa/population/publications/pdf/ageing/WPA2015_Re port.pdf

United Nations, Department of Economic and Social Affairs, Population Division. (2017). World population ageing 2017 highlights.

https://www.un.org/en/development/desa/population/publications/pdf/ageing/WPA2017_Hi ghlights.pdf

Visser, M. A., \& El Fakiri, F. (2016). The prevalence and impact of risk factors for ethnic differences in loneliness. European Journal of Public Health. https://doi.org/10.1093/eurpub/ckw115

Wagner, L. M., McDonald, S. M., \& Castle, N. G. (2012). Joint commission accreditation and quality measures in U.S. nursing homes. Policy, Politics \& Nursing Practice, 13(1), 8-16. https://doi.org/10.1177/1527154412443990 
Webber, R., Bowers, B., \& Bigby, C. (2014). Residential aged care for people with intellectual disability: A matter of perspective: Residential aged care for people with ID. Australasian Journal on Ageing, 33(4), E36-E40. https://doi.org/10.1111/ajag.12086

Weldrick, R., \& Grenier, A. (2018). Social isolation in later life: Extending the conversation. Canadian Journal on Aging, 37(1), 76-83. https://doi.org/10.1017/S071498081700054X

World Health Organization. (2015). World report on ageing and health. WHO: Geneva. https://apps.who.int/iris/bitstream/handle/10665/186463/9789240694811_eng.pdf?sequence $=1$ 